\title{
AVALIAÇÃO DA ATIVIDADE ANTIMICROBIANA IN VITRO DO ÓLEO ESSENCIAL DE Eucalyptus urograndis EM CEPAS PADRÃO DE BACILOS GRAM NEGATIVOS
}

\author{
EVALUATION OF IN VITRO ANTIMICROBIAL ACTIVITY OF Eucalyptus \\ urograndis ESSENTIAL OIL IN STANDARD CEPAS OF NEGATIVE GRAM \\ BACILLI
}

Franciele Mylena Esteves ${ }^{1 *}$, Alessandra Barrochelli da Silva Ecker ${ }^{2}$

1 Acadêmica do Curso de Graduação em Biomedicina da UNINGÁ - Centro Universitário Ingá, Maringá - PR.

2 Farmacêutica, Especialista em Farmacologia Oncológica pelo Hospital Erasto Gaertner/Curitiba, Mestre em Biociências aplicadas em Fisiologia pela UEM. Docente do Centro Universitário Ingá, Maringá-PR.

* Rodovia PR 317, n 6114, Saída para Astorga, Maringá-PR, CEP 87035-510. Email: franciele.mylena@outlook.com

Submetido em: 29/11/2019; Aceito em: 23/03/2020.

\section{RESUMO}

Infecções de origem clínica contemplam uma ampla variedade de bactérias com resistência a antimicrobianos, sendo um exemplo Escherichia coli e Pseudomonas aeruginosa, esses bacilos gram-negativas (BGN) causam com regularidade infecções no trato urinário. Grandes quantidades de fármacos obtidos através da síntese orgânica têm sido utilizadas no tratamento de infecções, o gênero Eucalyptus tem eficácia no combate de afecções das vias respiratórias, dores de estômago, diabetes, cistites e diarreia. Sendo primordial a avaliação da composição química, atividades antioxidante e antimicrobiana, uma vez que determinará a bioatividade de cada óleo essencial. O objetivo desse trabalho foi avaliar a atividade antimicrobiana do óleo essencial de Eucalyptus urograndis em cepas padrão de bacilos gram-negativos. O óleo foi extraído pelo método de Clevenger, e o teste de susceptibilidade antibacteriana in vitro foi realizada através do método de microdiluição em caldo, de acordo com o Clinical and Laboratory Standards Institute (M27-A3), com modificações. A análise do óleo demostrou predomínio do composto citronelol que possui atividade antimicrobiana. Foram testadas duas cepas padrão: Escherichia coli ATCC 25922 e Pseudomonas aeruginosa ATCC 27853. Foi realizada a Concentração Inibitória Mínima (CIM) em placas de 96 poços e alíquotas foram semeadas em Mueller Hinton ágar para confirmar o crescimento. A CIM para ambas as bactérias analisadas se mostrou sensível, sendo os valores obtidos para $P$.aeruginosa considerados com maior relevância. O uso do óleo essencial de E.urograndis mostrou-se eficaz como agente antimicrobiano, podendo ser considerado no desenvolvimento de novos antibacterianos.

Palavras-chave: Antimicrobianos. Eucalyptus. Óleo de Eucalipto. Testes de Susceptibilidade Microbiana. 


\section{ABSTRACT}

Clinical Infectious Diseases encompass a wide range o antimicrobial-resistant bacteria. Take Escherichia coli and Pseudomonas aeruginosa, for example. These gram-negative bacilli (GNB) frequently cause Urinary Tract Infection. There is a great number of organic synthesized drugs that have been used as a treatment for infections. The Eucalyptus genus is an effective combatant against airway disorders, stomach aches, diabetes, cystitis, and diarrhea. The chemical composition evaluation and the antioxidant and antimicrobial activities are paramount in determining the bioactivity of each essential oil. This project aims at evaluating the antimicrobial activity of essential Eucalyptus urograndis oil in standard strains of gram-negative bacilli. The Clevenger method was used to extract the oil. To perform the in vitro Antimicrobial Susceptibility Test we've adapted and used a microdilution method in accord with the Clinical and Laboratory Standards Institute (M27-A3). The results from the oil analysis show a dominance of citronellol, an active antimicrobial compound. There were two standard strains tested: Escherichia coli ATCC 25922 and Pseudomonas aeruginosa ATCC 27853. Minimum Inhibitory Concentration (MIC) was performed on 96-well plates, and aliquots were seeded on Mueller-Hinton agar to confirm growth. The MIC was sensitive for both bacteria, and the values obtained for $P$. aeruginosa were more relevant. Using E.urograndis essential oil proved to be effective as an antimicrobial agent and could be taken into consideration for the development of new antibacterial.

Keywords: Anti-Infective Agents. Eucalyptus. Eucalyptus Oil. Microbial Susceptibility Tests.

\section{INTRODUÇÃO}

Os agentes patológicos que podem culminar em infecções de origem clínica e alimentar são uma preocupação na área da saúde, já que algumas cepas destes microrganismos se mostram resistentes aos agentes desinfetantes que se tem disponível atualmente (DAVIDSON; HARRISON, 2002). Quando se trata de infecções de origem clínica se conhece uma grande variedade de bactérias que apresentam resistência aos antimicrobianos, mesmo que o mecanismo de ação dessas drogas comporte-se de forma diferente uma exposição indiscriminada ou até um contato com pessoas contendo diferentes tipos de infeções podem permitir que se estabelecesse uma resistência. Essa resistência acontece quando ocorrem mutações espontâneas e recombinação gênica gerando variabilidade genética, que por intermédio da ação natural seleciona as cepas de maior resistência. Como consequência dessas mutações a funcionalidade dessas drogas fica prejudicada o que renova $O$ interesse pela busca de antimicrobianos alternativos (SANTOS; PICCOLI; TEBALDI, 2017).

Entre os microrganismos que podem culminar em alguma patologia para os seres humanos se encontram os bacilos gram-negativos (BGN) Escherichia coli e Pseudomonas aeruginosa, que tem como característica comum causar infeção no trato urinário. E.coli pertence à família Enterobacteriaceae, é um 
bacilo fermentador de glicose na natureza, sendo dividido em seis categorias patogênicas, que abrangem cepas que produzem toxinas que podem causar diarréias, a outras que quando acometem tecidos estéreis geram infecção. São os aeróbios comensais mais encontrados no trato intestinal dos seres humanos e outros animais, não agindo de forma patogênica, tendo uma ação fisiológica favorável para o funcionamento do organismo (SOUZA et al., 2016). $P$. aeruginosa é um bacilo não fermentador da glicose e classifica-se como o principal microrganismo que causa infecções hospitalares, já que este bacilo que é um patógeno oportunista com capacidade de se habituar a alterações no ambiente e de desenvolver resistência a múltiplos fármacos (TAVARES, 2002).

As cefalosporinas (CEF) são uma classe de antimicrobianos que apresenta uma diversificada gama de fármacos que são classificados por geração, sendo as de terceira e quarta geração aquelas que têm melhor ação frente a BGN facultativos, são antimicrobianos B-lactâmicos de amplo espectro que tem como atividade bactericida a inibição da síntese da parede celular, estando disponíveis para uso no Brasil por via de administração parenteral, e incluem as subclasses ceftazidima (CAZ), ceftriaxona (CRO) e cefotaxima (CTX) (ANVISA, 2007).

O uso de CRO é indicado em casos de infecções em variados graus de acometimento, que englobam sepse para neonatos e microrganismos sensíveis em adultos, tendo uma atividade muito mais ativa em casos de infeções por Enterobacteriaceae como a E. coli (CEFTRIAXONA, 2015). Faz-se uso da CAZ em infecções simples e até múltiplas (CEFTAZIDIMA, 2016), podendo segundo a Agência Nacional de Vigilância Sanitária (ANVISA) agir contra $P$. aeruginosa já que consegue penetrar no sistema nervoso central, o que a torna uma alternativa para o tratamento de meningites promovidas por esta bactéria, já que este agente tem uma alta resistência frente às outras cefalosporinas desta classe. Alguns estudos demonstram que alguns espécimes clínicos têm desenvolvido mecanismo de resistentes a cefalosporinas de $3^{\underline{a}}$ geração (KESSLE, 2001).

$\mathrm{Na}$ tentativa de garantir a inocuidade desses antimicrobianos tem se estudado cada vez mais a atividade de óleos essenciais (OEs) de diversas espécies de plantas, já que estes possuem atividade antimicrobiana. Os OEs constituem da mistura de compostos voláteis, que contem inúmeros constituintes químicos individuais, que podem apresentar atividade biológica (HORVÁTH, 2015).

Grandes quantidades de fármacos obtidas através da síntese orgânica têm sido utilizadas no tratamento de infecções, o gênero Eucalyptus tem eficácia no combate de afecções das vias respiratórias, dores de estômago, diabetes, cistites e diarréia (FIGUEIREDE et al., 2013). Fatores que geram o interesse em ampliar o conhecimento das espécies para se avaliar sua composição química, atividades antioxidante e antimicrobiana, uma vez que determinará a bioatividade de cada OEs (GHAFFAR et al., 2015).

A espécie Eucalyptus urograndis é um híbrido do cruzamento entre Eucalyptus urophylla com Eucalyptus grandis, sendo uma espécie bastante utilizada para cultivo no Brasil já que se adapta bem a diferentes condições climáticas e resiste bem às doenças (CARDOSO et al., 2019). Os OEs desse gênero de planta são sintetizados nas folhas por meio de células secretoras, 
que também o armazenam (VITTI; BRITO, 2003). Encontram-se na literatura dados acerca da atividade antimicrobiana de várias espécies de eucalipto, sendo, no entanto poucos os estudos sobre a ação do híbrido E.urograndis (ESTASNILAU et al., 2001; CARDOSO et al., 2019; CORREA, 2019).

Baseado no exposto acima o objetivo desse trabalho foi avaliar a atividade antimicrobiana do óleo essencial de Eucalyptus urograndis em cepas padrão de $E$. coli e $P$. aeruginosa.

\section{MATERIAL E MÉTODOS}

\section{Extração do óleo essencial}

Foram utilizadas folhas jovens de E. urograndis coletadas no Núcleo de Agronomia Experimental (NEA), situado no Centro Universitário Ingá-Uningá na sede de Maringá, Paraná, Brasil no dia 12 de Abril de 2019. Sendo os experimentos conduzidos no Laboratório de Microbiologia e Hematologia Clínicas da Uningá no período de abril a setembro de 2019.

O óleo essencial das folhas de E. urograndis foi extraído por meio da técnica de hidrodestilação em aparelho Clevenger utilizando $40 \mathrm{~g}$ das folhas da planta em $500 \mathrm{~mL}$ de água destilada, sendo posteriormente tratato com sulfato de sódio anidro e armazenado em vidro de cor âmbar envolto por papel alumínio em geladeira para posterior uso. Uma amostra do óleo extraído foi enviada para determinação de sua constituição química pelo método de cromatografia gasosa no Departamento de Análises de Alimentos (DAALM) da Universidade Tecnológica Federal do Paraná - UTFPR.

\section{Atividade do óleo essencial de E.urograndis}

Foram realizadas diluições seriadas na razão 2 a partir de $900 \mu \mathrm{L}$ do óleo essencial de E.urograndis e $100 \mu \mathrm{L}$ de Tween 80 (solução pura) sendo utilizadas cepas padrão de Escherichia coli (ATCC 25922) e Pseudomonas aeruginosa (ATCC 27853), pertencentes ao Laboratório de Microbiologia e Hematologia Clínicas da UNINGÁ - Centro Universitário Ingá, que fornecem referências de origem e padrão definidos, semeadas por esgotamento em Ágar Mueller Hinton (MHA) incubadas por 18 horas em estufa bacteriológica a $35^{\circ}-\mathrm{C}$ $\pm 2^{\circ} \mathrm{C}$

Foram testadas em placas de microdiluição, a solução pura, bem como as diluições seriadas com igual volume de inóculo bacteriano ajustado na escala 0,5 de MacFarland, permanecendo em estufa $\left(35^{\circ}-\mathrm{C} \pm 2^{\circ} \mathrm{C}\right)$ e a leitura visual após 24 horas

Foi realizada a confirmação da atividade do OE em cada diluição testada transferindo assepticamente com pipeta automática $20 \mu \mathrm{L}$ dos volumes de cada teste realizado nas microplacas para placas contendo MHA, sendo estas armazenadas em estufa bacteriológica por 24 horas com verificação do crescimento de colônias.

\section{Determinação da MIC}

Para esse experimento realizou-se o método de microdiluição em caldo com algumas modificações, com base na Metodologia dos Testes de Sensibilidade aos Agentes Antimicrobianos por Diluição para Bactérias de 
Crescimento Aeróbico, padronizada pelo National Committee for Clinical Laboratory Standards (CLSI, 2020).

Foram testadas duas diluições acima e duas abaixo da sensibilidade estabelecida no CLSI e conforme podemos verificar na Tabela 1.

Tabela 1 - Interpretação da sensibilidade em relação aos antimicrobianos testados.

\begin{tabular}{lcccccc}
\hline \multirow{2}{*}{ CEPAS } & \multicolumn{3}{c}{ Ceftazidima } & \multicolumn{3}{c}{ Ceftriaxona } \\
\cline { 2 - 7 } & $\mathrm{S}$ & $\mathrm{I}$ & $\mathrm{R}$ & $\mathrm{S}$ & $\mathrm{I}$ & $\mathrm{R}$ \\
\hline Escherichia coli & $<4$ & 8 & $\geq 16$ & $<1$ & 2 & $\geq 4$ \\
\hline Pseudomonas aeruginosa & $<8$ & 16 & $\geq 32$ & $-^{*}$ & $-^{*}$ & $-^{*}$ \\
\hline
\end{tabular}

Notas: (S) Sensível (I) Intermediário (R) Resistente - Não produz ação inibitória.

Fonte: As autoras. CLSI 2020.

Os antimicrobianos Ceftazidima (CAZ) e Ceftriaxona (CRO) utilizados, foram previamente esterilizados por filtração de membranas e estocados congelados na concentração de $1000 \mu \mathrm{g} / \mathrm{mL}$ até sua decorrente aplicação. Foram adicionados $50 \mu \mathrm{L}$ de caldo MHB nos poços das colunas de 2 a $12 \mathrm{em}$ placa de 96 poços (KASVI); $100 \mu \mathrm{L}$ do respectivo fármaco no poço de número 1 e transferido $50 \mu \mathrm{L}$ entre os poços e homogeneizado por dez vezes. Na placa já preparada com as diluições do antimicrobiano, foi inserido $50 \mu \mathrm{L}$ do inóculo padronizado de cada cepa padrão nos poços de 2 a 12.

As placas foram incubadas a $35^{\circ}-\mathrm{C} \pm 2^{\circ} \mathrm{C}$ com leitura após 24 horas. $\mathrm{O}$ crescimento bacteriano foi avaliado visualmente sendo confirmado através da transferência asséptica de $20 \mu \mathrm{L}$ de cada diluição testada com pipeta automática para placas contendo MHA sendo estas armazenadas em estufa e com leitura após 24 horas com verificação do crescimento de colônias.

\section{RESULTADO E DISCUSSÃO}

A análise da composição química do óleo essencial de E. urograndis obtida por cromatografia gasosa realizada no DAALM revelou 18 constituintes que estão dispostos na Tabela 2.

Os compostos encontrados em maior quantidade foram os monoterpenos, citronelal $(81,13 \%)$ e isopulegol (15,50\%). O citronelal é um dos principais componentes encontrado em óleos essenciais de plantas aromáticas, como as do gênero Eucalyptus, sendo capaz de promover atividade antimicrobiana (MARCO et al., 2007; QUINTANS-JÚNIOR et al., 2011; ZORE et al., 2011). Alguns estudos demonstram que este composto possui atividades anti-inflamatórias e antinociceptiva (MELO et al., 2010; QUINTANS-JÚNIOR et al., 2010). Outros constituintes encontrados na amostra em menor quantidade que também chamam a atenção por apresentarem propriedades biológicas que incluem atividade antimicrobiana (GAYOSO et al., 2004; LIMA et al., 2005), são os pinenos a-pineno $(0,22 \%)$ e $\beta$-pineno $(0,50 \%)$, utilizados na composição de cosméticos e produtos de limpeza (LETIZIA et al., 2003). 
Tabela 2 - Constituintes do óleo essencial de E. urograndis.

\begin{tabular}{lc}
\hline \multicolumn{1}{c}{ Constituintes } & Concentração em \% \\
\hline 1-Butinol,3- metil-3- (1- metiletoxi) & 0.10 \\
Ácido acético, trifuoro-,2,2-dimetilpropil & 0.06 \\
a-Pineno & 0.22 \\
ß-Pineno & 0.50 \\
Etana, 1-(4-metilfenil) & 0.08 \\
5-Hepten-2-ona, 6-metil & 0.28 \\
Ácido propanoico, 2-hidroxi-2metil & 0.12 \\
4-Hexen-1-ol, acetato & 0.05 \\
Etanona, 1-ciclopropil-2-(4-piridinil) & 0.08 \\
4,4-Dimeil-1-hexeno & 0.14 \\
2H-Pirano, tetra-hidro-4-metil-2-(2-metil) & 0.37 \\
2-Penten-2-ona & 0.07 \\
Citronelal & 81.13 \\
Isopulegol & 15.50 \\
2,6,10- Trimetilundeca-1,3-dieno & 0.54 \\
Propanoato de 2-buteno-1-ol & 0.19 \\
1,3,6,10-Dodecatetraeno,3,7,11-trimetil & 0.21 \\
1-Penteno, 5- (2,2- dimetilciclopropil) & 0.36 \\
\hline
\end{tabular}

Fonte: As autoras. Departamento de Análises de Alimentos (DAALM) da Universidade Tecnológica Federal do Paraná - UTFPR.

Araújo (2010) encontrou 10 constituintes no óleo essencial de $E$. urograndis, sendo os de maior concentração o orto-cimeno (41,4\%), 1,8-cineol $(25,8 \%)$ e $\alpha$-terpineol $(1,4 \%)$, que são usados como fragrância e aroma, e possuem atividade inseticida.

Doran (1991) classificou o híbrido E. urophylla $\times$ E. grandis com teor de $33 \%$ de 1,8-cineol. O monoterpeno 1,8-cineol é utilizado na indústria farmacêutica, já que apresenta ação anestésica, antibronquítica, antisséptica, bactericida, expectorante e, também, atividades herbicida e insetífuga. No entanto este composto não foi identificado no óleo obtido, o que segundo Ogunwande (2003) seria uma peculiaridade em espécies de E.grandis.

Pereira (2010) descreve acerca das diferenças de composição e proporções dos componentes dos OEs podem variar entres espécimes, que independente do seu controle genético podem sofrer modificações em resposta á diferença de condições de cultivo, de ambiente, idade da planta e suas características genéticas (COSENTINO et al., 1999; DARROW; BOWWERS, 1997).

A natureza dos constituintes e a sua concentração no óleo podem interferir diretamente na sua atividade biológica (BROOKER; KLEINIG, 2006), sendo possível que até as moléculas de menor proporção modulem a ação dos principais componentes (HOET et al., 2006).

Alguns estudos promovidos compararam a atividade antibacteriana do óleo essencial extraído de algumas espécies de Eucalyptus, com o uso isolado de seus compostos majoritários como o 1,8-cineol, a-pineno e citronelal, podendo concluir que os compostos quando usados individualmente possuem menor atividade do que o próprio óleo essencial, consolidando que a 
combinação dos constituintes é importante para a atividade antimicrobiana do óleo de eucalipto (CIMANGA et al., 2002).

Como podemos verificar a determinação da CIM em meio líquido em que foi testada a ação do óleo essencial de $E$. urograndis para os bacilos gramnegativos promoveu uma inibição do crescimento bacteriano. Para $P$. aeruginosa a capacidade de inibição aconteceu na diluição de 1:16 conforme podemos verificar na Figura 1.

A concentração efetiva do OE $(16 \mu \mathrm{g} / \mathrm{mL})$ em $P$. aeruginosa foi menor do que a CIM da CAZ $(64 \mu \mathrm{g} / \mathrm{mL})$, antimicrobiano amplamente utilizado no tratamento em infecções ocasionadas pelo bacilo não fermentador de glicose, 0 que demonstra uma possibilidade do uso do composto extraído.

Em relação $\mathrm{CRO}$, o resultado é até mais promissor já que este antimicrobiano não é efetivo contra $P$. aeruginosa e conforme observamos na Figura 1, a ação do OE é efetiva na concentração de $16 \mu \mathrm{g} / \mathrm{mL}$.

Figura 1 - Determinação da CIM e ação do óleo essencial de $E$. urograndis em cepa padrão de Pseudomonas aeruginosa.

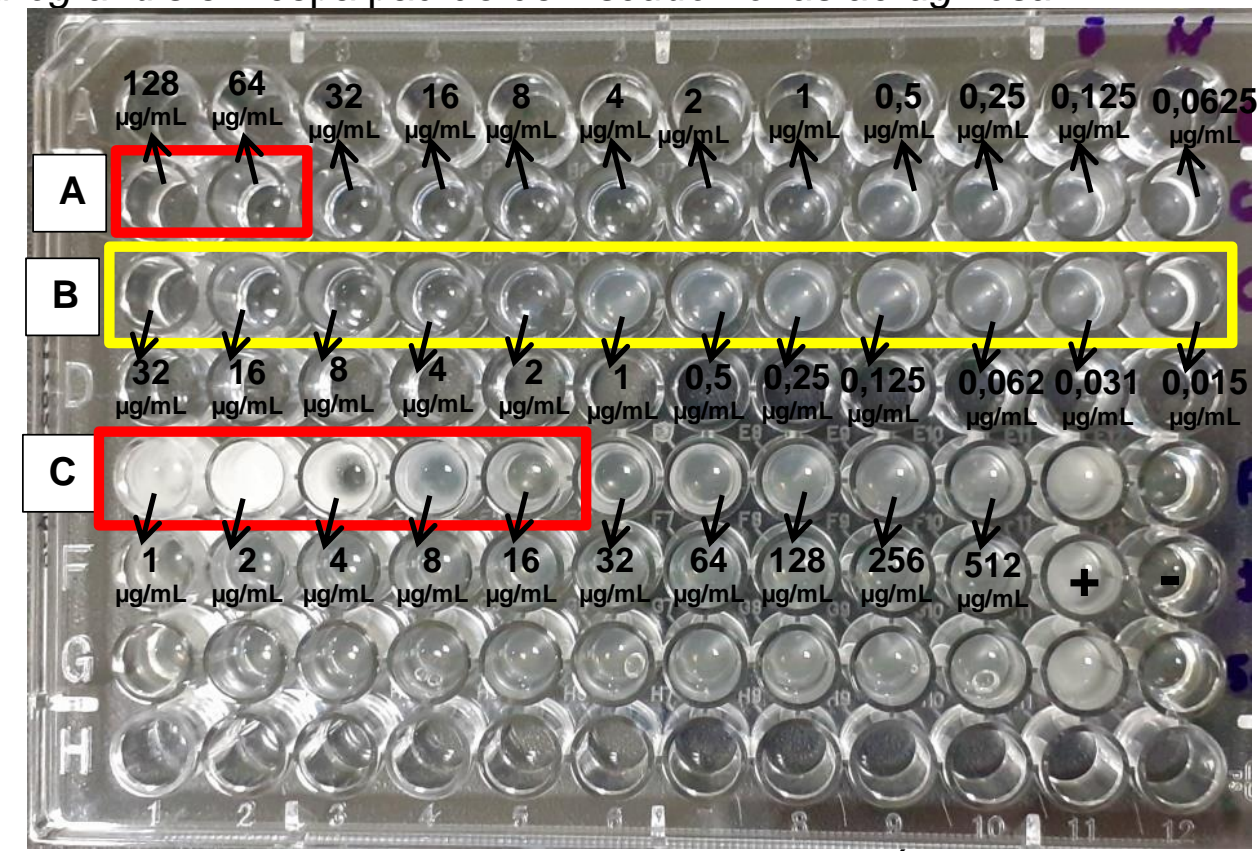

Notas: (A) CIM ceftazidima. (B) CIM ceftriaxona. (C) Óleo de E. urograndis.

Fonte: As autoras.

Já em relação $E$. coli, podemos verificar que o OE teve uma ação inibitória apenas na concentração de $256 \mu \mathrm{g} / \mathrm{mL}$, valor bem maior do que as CIM dos antimicrobianos CAZ $(8 \mu \mathrm{g} / \mathrm{mL})$ e CRO $(0,5 \mu \mathrm{g} / \mathrm{mL})$, conforme podemos verificar na Figura 2.

$\mathrm{Na}$ Tabela 3, podemos verificar que OE é capaz de inibir o crescimento de ambas bactérias, a concentração necessária para ter sua ação na enterobactéria é bem maior quando comparamos com a CIM dos antibióticos testados. 
Figura 2 - Determinação da Concentração Inibitória Mínima para cepa padrão de E. coli e ação do óleo essencial de E. urograndis.

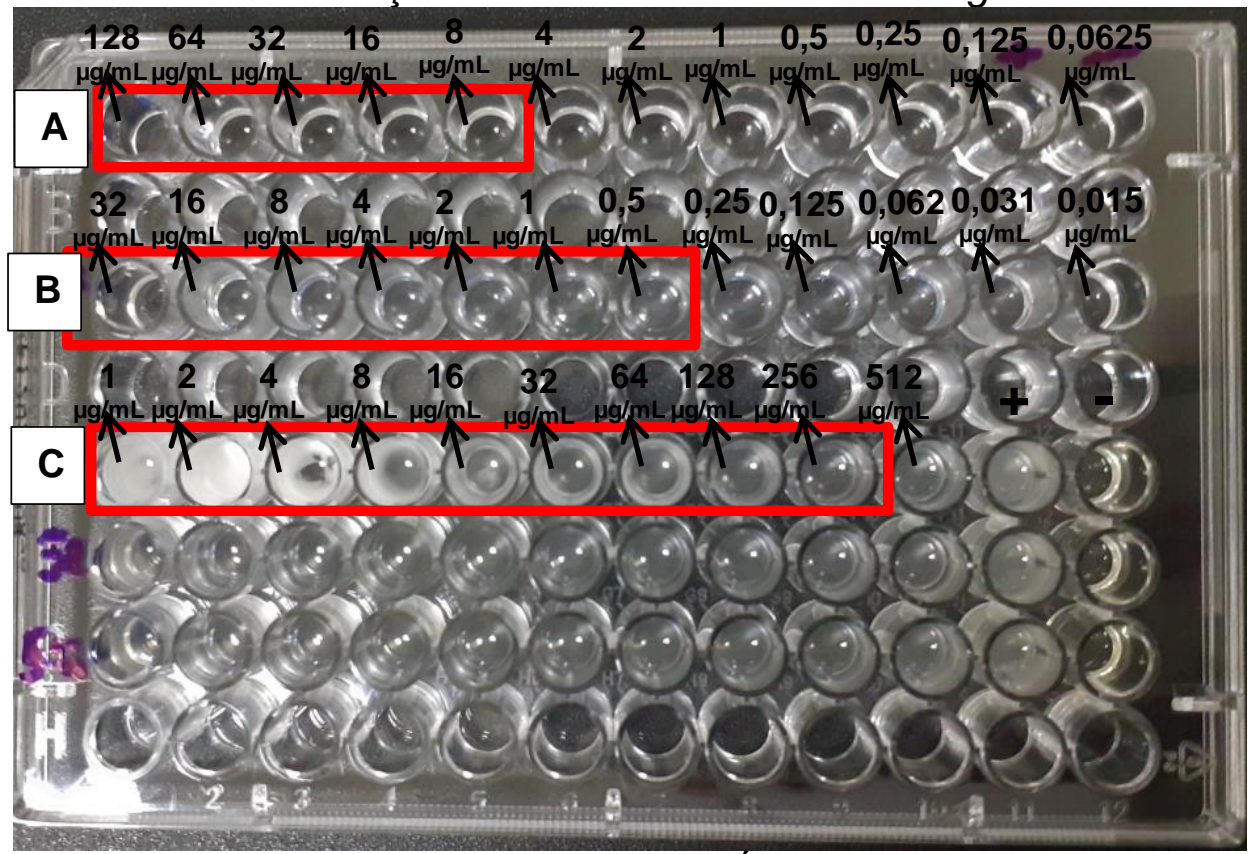

Notas: $(A)$ ceftazidima $(B)$ ceftriaxona $(C)$ Óleo de E. urograndis.

Fonte: As autoras.

Tabela 3 - Comparativo da concentração efetiva do Óleo essencial de $E$. urograndis e dos antibióticos testados em relação as bactérias gram-negativas

\begin{tabular}{cccc}
\hline \multirow{2}{*}{ CEPAS } & $\begin{array}{c}\text { Óleo essencial } \boldsymbol{E} . \\
\text { urograndis }\end{array}$ & Ceftazidima & Ceftriaxona \\
\cline { 2 - 4 } $\begin{array}{c}\mathrm{CIM} \mu \mathrm{g} / \mathrm{mL} \\
\text { (ATCC 27853) }\end{array}$ & 16 & $\mathrm{CIM} \mu \mathrm{g} / \mathrm{mL}$ & $\mathrm{CIM} \mu \mathrm{g} / \mathrm{ml}$ \\
\hline E. coli & 256 & 32 & $-^{*}$ \\
(ATCC 25922) & & 8 & 0,5 \\
\hline
\end{tabular}

Notas: * Não se observou atividade antimicrobiana.

Fonte: os autores.

A confirmação do crescimento bacteriano na microdiluição em caldo foi realizada através da semeadura das concentrações testadas em placas contendo MHA que confirmaram os valores da ação do OE observados nas placas conforme demonstrado na Figura 3.

Pseudomonas spp. é facilmente encontrada no ambiente hospitalar já que pode sobreviver em locais com elevada umidade, sendo possível o seu desenvolvimento em equipamentos e materiais hospitalares, em sua maioria os que possuem componentes líquidos, um bom exemplos são germicidas como sabonetes líquidos e desinfetantes (CAETANO et al., 2011; BLANC et al., 2016) que apresentam contaminação pelo uso incorreto, ou até por algum erro durante o processo de fabricação ou estocagem (CUNHA et al., 2017). 
Figura 3 - Confirmação da ação óleo essencial de E. urograndis sobre as cepas padrão de Escherichia coli e Pseudomonas aeruginosa.

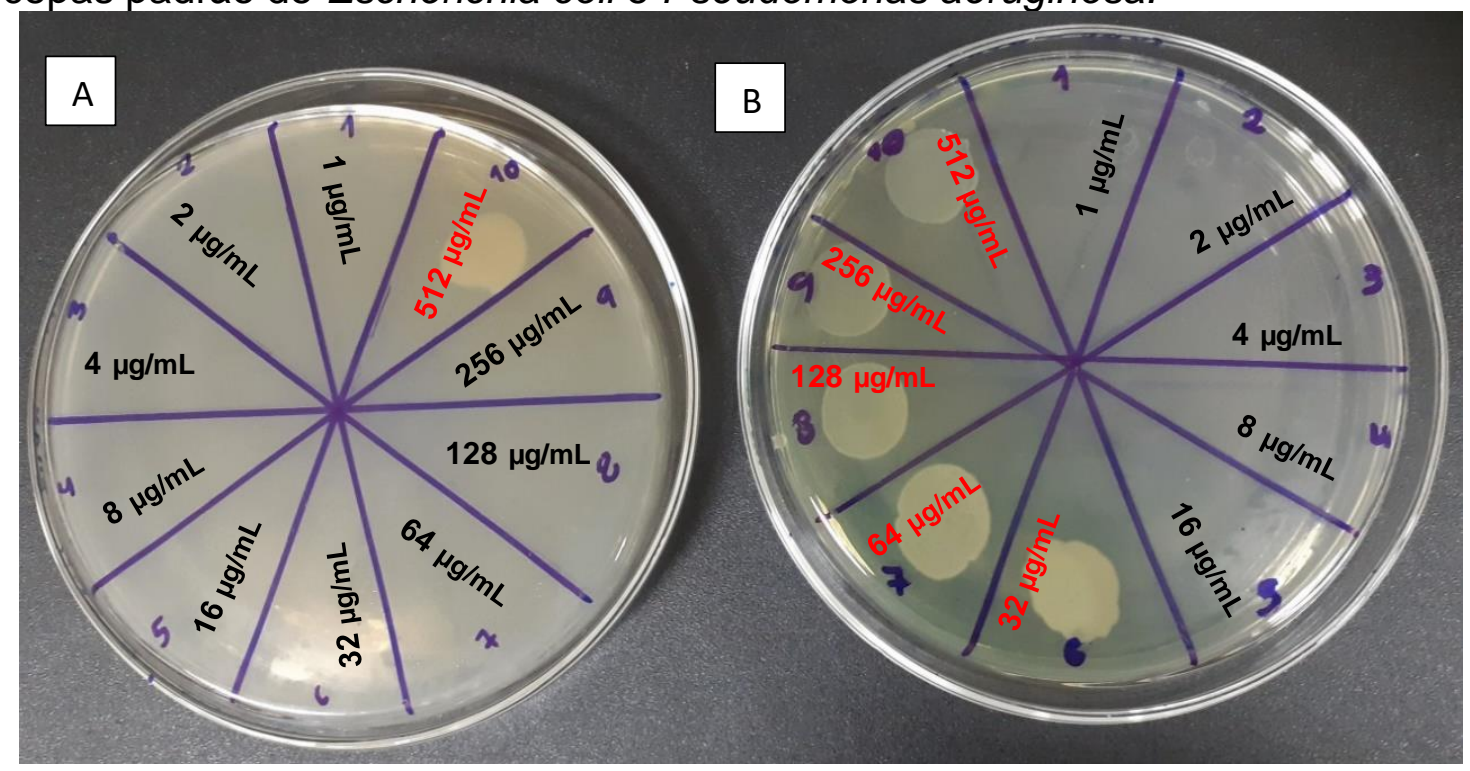

Notas: (A) E. coli. (B) P. aeruginosa.

Fonte: As autoras.

Serufo (2007) realizou um monitoramento nos sabonetes líquidos e antissépticos em uso em 27 hospitais brasileiros da Rede Sentinela. Foram testadas um total de 1196 amostras, das quais em 16 delas foi identificada a presença de $P$. aeruginosa, sendo em 12 amostras de sabonete líquido e em 4 amostras de sabonete antisséptico.

Um estudo realizado em um hospital de médio porte de Fortaleza/CE analisou 59 frascos de sabão líquido, onde em 33 deles apresentaram contaminação bacteriana, sendo que $P$. aeruginosa foi identificada em 3 amostras analisadas (CAETANO et al., 2011).

Já o estudo elaborado por Pereira (2008) teve como objetivo a produção de sabão líquido, onde foram utilizados como matéria-prima óleos alimentares e sendo incorporado o óleo essencial de eucalipto e outros OEs com o intuito de promover uma fragrância e estabilidade dos óleos pelo uso de casca de amêndoas. Não sendo, no entanto determinado se este sabão apresentou atividade antisséptica.

Uma outra utilização para o OE de eucalipto seria em associação a antimicrobianos. A espécie Eucalyptus globulos apresentou efeito antagonista quando associado a eritromicina e testado em Streptococcus mutans (ALVES, 2011), já o Eucalyptus citriodora apresentou sinergismo na associação à tetraciclina frente $P$. aeruginosa (OLIVEIRA, 2006). Sendo assim, se entende que as características para que o óleo exerça alguma interferência na ação de antibióticos dependera do tipo de antibiótico, da cepa bacteriana, e do OE que está sendo incorporado.

\section{CONCLUSÃO}

Os resultados deste estudo sugerem que o uso do OE extraído das folhas de Eucalyptus urograndis pode indicar uma possível alternativa no 
tratamento de infecções promovidas por bacilos gram-negativos resistentes aos antibióticos convencionais. Entretanto, são necessários mais estudos sobre os constituintes e sua ação antimicrobiana para que se possa determinar a melhor forma de se utilizar desta substância.

\section{REFERÊNCIAS}

ALVES, L. A. et al. Interferência de óleos essenciais sobre antibióticos utilizados no tratamento de infecções da cavidade oral. IJD. International Journal of Dentistry, v. 10, n.1, p. 26-31, 2010.

ANVISA. AGÊNCIA NACIONAL DE VIGILÂNCIA SANITÁRIA. Antimicrobianos - Bases teóricas e uso clínico. 2007.

ARAÚJO, F. O. L. et al. Constituintes químicos e efeito ecotoxicológico do óleo volátil de folhas de Eucalyptus urograndis (Mirtaceae). 2010.

BHATIA, S. P. et al. Revisão de material de fragrância em isopulegol. Toxicologia Alimentar e Química, v. 46, n. 11, p. S185-S189, 2008.

BLANC, D. S. et al. Hand soap contamination by Pseudomonas aeruginosa in a tertiary care hospital: no evidence of impact on patients. Journal of Hospital Infection, v. 93, n. 1, p. 63-67, 2016.

BROOKER, M. I. H. et al. Guia de campo para eucaliptos. Volume 3. Sudeste da Austrália. Inkata Press Pty Ltd, 2006.

BRUNETON, J. Elementos de fitoquímica y de farmacognosia. Editorial Acribia. Zaragoza, España, 1991.

BURT, S. Essential oils: their antibacterial properties and potential applications in foods-a review. International journal of food microbiology, v. 94, n. 3, p. 223-253, 2004.

CAETANO, J. A. et al. Identificação de contaminação bacteriana no sabão líquido de uso hospitalar. Revista da Escola de Enfermagem da USP, v. 45, n. 1, p. 153-160, 2011.

CARDOSO, R. C. et al. Potencial Antimicrobiano do Óleo da Folha de Eucalyptus urograndis Frente Stafilococus aureus. Id on Line Revista Multidisciplinar e de Psicologia, v. 13, n. 43, p. 989-1002, 2019.

CEFTAZIDIMA. Paulo Fernando Bertachini. Goiás: Aurobindo Pharma Indústria Farmacêutica Ltda, 2016. Bula de remédio. 
CEFTRIAXONA SÓDICA. Paulo Fernando Bertachini. Goiás: Aurobindo Pharma Indústria Farmacêutica Ltda, 2015. Bula de remédio.

CHEN, Y. et al. Ésteres saturados de isopulegol de cadeia longa como novos potenciadores de permeação para administração transdérmica de drogas. Pesquisa farmacêutica, v. 31, n. 8, p. 1907-1918, 2014.

CIMANGA, K. et al. Correlação entre composição química e atividade antibacteriana de óleos essenciais de algumas plantas medicinais aromáticas em crescimento na República Democrática do Congo. Jornal de etnofarmacologia, v. 79, n. 2, p. 213-220, 2002.

CLINICAL AND LABORATORY STANDARDS INSTITUTE (CLSI). Performace Standards for Antimicrobial Susceptibility. 30ed. 2020.

CORREA, M. S. et al. Antimicrobial and antibiofilm activity of the essential oil from dried leaves of Eucalyptus staigeriana. Arquivos do Instituto Biológico, v. $86,2019$.

COSENTINO, S. et al. Atividade antimicrobiana in vitro e composição química de óleos essenciais do timo da Sardenha. Cartas em microbiologia aplicada, v. 29, n. 2, p. 130-135, 1999.

CUNHA, E. A. et al. Evaluation of Extrinsic Contamination of Liquid Soap Used for Handwashing in a Philanthropic Hospital. Revista Brasileira de Ciência Médicas e da Saúde, v. 6, n. 6, p. 1-5, 2017.

DARROW, K.; BOWERS, M. D. Variação fenológica e populacional nos glicosídeos iridoides de Plantago lanceolata (Plantaginaceae). Sistemática e Ecologia Bioquímica, v. 25, n. 1, p. 1-11, 1997.

DAVIDSON, P. M.; HARRISON, M. A. Resistance and adaptation to food antimicrobials, sanitizers, and other process controls. Food TechnologyChampaign then Chicago, v.56, n.11, p.69-78, 2002.

ESTANISLAU, A. A. et al. Composição química e atividade antibacteriana dos óleos essenciais de cinco espécies de Eucalyptus cultivadas em Goiás. Revista Brasileira de Farmacognosia, v. 11, n. 2, p. 95-100, 2001.

FIGUEIREDE, A. C. et al. Óleos essenciais de espécies de Eucalyptus. Revista Tecnología agroalimentaria p. 96-100, 2013.

GAYOSO, C. W.; LIMA, E. O.; SOUZA, E. L. Ação inibitória do óleo essencial de Cinnamomum zeylanicumBlume, apineno e $\beta$-pineno sobre fungos isolados de onicomicoses. Jornal Brasileiro de Fitomedicina, v. 1, n. 1-4, p. 25-29, 2004. 
GHAFFAR, A. et al. Composição química e avaliação in vitro das atividades antimicrobiana e antioxidante de óleos essenciais extraídos de sete espécies de eucalipto. Molecules, v. 20, n. 11, p. 20487-20498, 2015.

HOET, S. et al. Compostos antitripanossômicos do óleo essencial de folhas de Strychnos spinosa. Planta medica, v. 72, n. 05, p. 480-482, 2006.

HORVÁTH, G.; ÁCS, K. Óleos essenciais no tratamento de doenças do trato respiratório, destacando seu papel nas infecções bacterianas e sua ação antiinflamatória: uma revisão. Diário de aromas e fragrâncias, v. 30, n. 5, p. 331341, 2015.

KESSLER, R. E. Cefepime microbiologic profile and update. The Pediatric infectious disease journal, v. 20, n. 3, p. 331-336, 2001.

KONEMAN, E. W.; ALLEN, S. D.; JANDA, W. M. Diagnóstico Microbiológico: Texto e Atlas Colorido. 5.ed. Rio de Janeiro: MEDSI, p.1465, 2000.

LETIZIA, C. S. et al. Fragrance material review on linalool. Food \& Chem Toxicol v. 4, p. 943-964, 2003.

LIMA, I. O. et al. Efeito inibitório de alguns fitoconstituintes sobre o crescimento de leveduras potencialmente causadoras de infecções oportunistas. Revista Brasileira de Ciências Farmacêuticas, v. 41, n. 2, p. 199-203, 2005.

MARCO, C. A. et al. Características do óleo essencial de capim-citronela em função de espaçamento, altura e época de corte. Horticultura brasileira, v. 25, n. 3, jul.-set, 2007.

MELO, M. S. et al. Antinociceptive effect of citronellal in mice. Pharmaceutical biology, v. 48, n. 4, p. 411-416, 2010.

OGUNWANDE, I. A. et al. Chemical composition of the essential oils from the leaves of three Eucalyptus species growing in Nigeria. Journal of Essential Oil Research, v. 15, n. 5, p. 297-301, 2003.

OLIVEIRA, R. D. et al. Estudo da interferência de óleos essenciais sobre a atividade de alguns antibióticos usados na clínica. Revista Brasileira de Farmacognosia, v. 16, n. 1, p. 77-82, 2006.

OSTROSKY, E. A. et al. Métodos para avaliação da atividade antimicrobiana e determinação da concentração mínima inibitória $(\mathrm{CMI})$ de plantas medicinais, Revista Brasileira de Farmacognosia, v. 18, n. 2, p. 301-307, 2008.

PEREIRA, A. M. S. et al. Produção de sabões líquidos com aroma e esfoliante a partir de óleos usados da cantina da FEUP. 2008. 
PEREIRA, J. L. Composição química dos óleos essenciais de espécies de Eucalyptus L'Herit (Myrtaceae). Universidade Federal de Viçosa, 2010.

QUINTANS-JÚNIOR, L. et al. Antinociceptive Action and Redox Properties of Citronellal, an Essential Oil Present in Lemongrass. Journal of Medicinal Food, v. 14, n. 6, p. 630-639, 2011.

QUINTANS-JÚNIOR, L. J. et al. Carvacrol,(-)-borneol and citral reduce convulsant activity in rodents. African Journal of Biotechnology, v. 9, n. 39, p. 6566-6572, 2010.

SANTOS, C. H. S.; PICCOLI, R. H.; TEBALDI, V. M. R. Atividade antimicrobiana de óleos essenciais e compostos isolados frente aos agentes patogênicos de origem clínica e alimentar. Revista Instituto Adolfo Lutz, v. 76, p. e1719, 2017.

SANTOS, V. M. C. S.; SCHNEIDER, T. R.; BIZZO, H. R. Alternativas de propagação na produção de óleo essencial de Mentha canadensis L. no Litoral Norte Catarinense. Revista Brasileira de Plantas Medicinais, vol. 14, n. 1, p. 97-10, 2012.

SAHM, D. F.; WASHINGYON II, J. A. Antibacterial susceptibility tests: Dilution methods. In: BALOWS, A. et al. Manual of clinical microbiology. 5.ed. Washington, DC: American Society for Microbiology, p. 1105-1116, 1991.

SERUFO, J.C. et al. Avaliação da dinâmica de contaminação extrínseca de sabonetes líquidos e anti-sépticos no processo de uso em hospitais brasileiros da rede sentinela. 2007.

SOUZA, C. O. et al. Escherichia coli enteropatogênica: uma categoria diarreiogênica versátil. Revista Pan-Amazônica de Saúde, v. 7, n. 2, p. 79-91, 2016.

TAVARES, W. Manual de antimicrobianos e quimioterápicos antinfecciosos. 2002.

US Food and Drug Administration. Food and drug administration compliance program guidance manual: mycotoxins in domestic and imported foods. Maryland: Silver Spring, 2016.

VITTI, A. M. S.; BRITO, J. O. Óleo essencial de eucalipto. Documentos florestais, v. 17, p. 1-26, 2003.

ZORE, G. B. et al. Phytomedicine Terpenoids inhibit Candida albicans growth by affecting membrane integrity and arrest of cell cycle. European Journal of Integrative Medicine, v. 18, n. 13, p. 1181-1190, 2011. 